\title{
In-Silico structural analysis of wild-type human hemoglobin and its mutation resulting in sickle cell anemia
}

\author{
Soumitra Nath ${ }^{1,2}$, Nirmal Paul ${ }^{1}$, Manabesh Nath², Bibhas Deb ${ }^{1,2}$ \\ ${ }^{1}$ Bioinformatics Centre, Gurucharan College, Silchar, Assam, India, ${ }^{2}$ Department of Biotechnology, Gurucharan \\ College, Silchar, Assam, India
}

\section{A B S T R A C T}

Background: Hemoglobin $(\mathrm{HbA})$ is a metalloprotein having a heme prosthetic group, two $\alpha$-globin chains, and two $\beta$-globin chains. A point mutation in the $6^{\text {th }}$ position of wild-type HBB gene (GAG > GTG) substitutes Glutamic acid (E) to Valine (V) in the $\beta$-chains of hemoglobin molecule ( $\mathrm{HbS}$ ) resulting in Sickle Cell Anemia. Structural deformities in the $\beta$-globin gene leads to disruptive conformation of red blood cells, disturbs the oxygen transportation and causes functional abnormalities. Aims and Objective: The purpose of the study was to understand the structural, genetic and metabolic effect of the point mutation on HBB gene that causes sickle cell disease. Materials and Methods: The 3D structures of $\mathrm{HbA}$ and $\mathrm{HbS}$ proteins were retrieved from PDB and the changes in their physical properties were analyzed using Swiss PDB viewer and Molegro molecule viewer. Gene networks were constructed using GeneMANIA server to study genetic and metabolic interactions of the HBB gene. Results: In-silico studies showed that the normal bond length between Glu6-Glu7 in $\mathrm{HbA}$ molecule is $1.32 \AA$ and that of $\mathrm{HbS}$ is $1.33 \AA$. After comparing the two proteins, it was observed that sickle cell hemoglobin suffers a change in bond angle from $122.4^{\circ}$ in $\mathrm{HbA}$ to $119.35^{\circ}$ in HbS. Comparative energy minimization of Glu6 and Val6 in wild-type and mutant hemoglobin respectively yielded 8.78 and $-9.083 \mathrm{KJ} / \mathrm{mol}$ net energy values, suggesting a more reactive $\mathrm{HbA}$ and less reactive $\mathrm{HbS}$. Gene networks were determined on the basis of physical, genetic and co-expressive interactions of HBB gene which revealed a strong connection between HBB and HBA1 genes within the association constituted of various metabolic functions. Conclusion: Sickle cell disease results from a sequence of events which start with a single nucleotide substitution that ultimately leads to severe anemia and other cardiovascular problems. Incorporation of computational exercises correlates to a better probability of discovering precision medicine through target site-specific drug designing.
Access this article online

Website:

http://nepjol.info/index.php/AJMS

DOI: $10.3126 /$ ajms.v11i4.28486

E-ISSN: 2091-0576

P-ISSN: 2467-9100

Copyright (c) 2020 Asian Journal of Medical Sciences

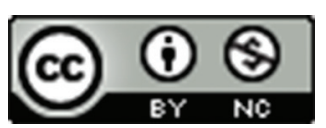

This work is licensed under a Creative Commons Attribution-NonCommercial 4.0 International License.

Key words: HbA; HbS; sickle cell anemia; In-silico

\section{INTRODUCTION}

Hemoglobin is a diverse superfamily of proteins detected in many animals and distributed mainly in red blood cells (RBCs). ${ }^{1}$ Hemoglobinopathies are inherited genetic disorders resulting from a mutation in globin gene that produces biological, structural and functional abnormalities. A single amino acid substitution is only confined to one aberration in the primary and secondary structure in hemoglobinopathy. The oxygen carrying capacity to all cells and tissues in the body is dependent upon hemoglobin which is the key constituent of Red Blood Cells (RBCs). The RBCs are regular and round in shape when it contains normal hemoglobin. A substitution mutation in the $6^{\text {th }}$ amino acid of $\beta$-chain of hemoglobin molecule concurrently changes glutamic acid (E) to valine (V), thereby causing structural deformities. This disruptive conformation of RBCs leads to sickle cell disease or sickle cell anemia. The homozygous and heterozygous states involving one hemoglobin gene encoding HbS protein 
is responsible for reduced red blood cell survival and hemolysis in Sickle Cell Disease (SCD). ${ }^{1}$ The occurrence of the autosomal recessive affected gene allele (heterozygous) in both parents who are asymptomatic carriers may transmit the defective gene to their child (homozygous, Hb SS) thereby resulting in the inheritance of SCD. ${ }^{2} \mathrm{HbS}$ forms highly crystallized structure under low oxygen pressure conditions which lead to pathological or physical stress. The formation of intracellular crystals cause polymerization of RBCs resulting in reduced oxygen uptake, as well as blocking of small blood vessels which promote RBC dehydration. ${ }^{3}$ The impact of RBC sickling and polymerization in sickle cell trait is considered to be the primary factor responsible for vaco-occlusive crises. The other dysfunction includes severe tissue hemolysis, ischemia, inflammation, hypoxia, endothelial injury, increased viscosity, acidosis and hypothermia. ${ }^{4}$ Approximately, 2,00,000 babies in Africa each year are born with severe autosomal sickle cell genotype that constitutes hemoglobinopathies worldwide, ${ }^{5}$ but the frequency of occurrence of sickle cell mutation in sub-Saharan Africa, middle-East and scattered populations throughout India is apparently up to $18 \%{ }^{6}$ In developed countries, preventive measures have been implemented to bring down the progressive survival loss amongst patients originating from North America, United Kingdom, and other European countries. ${ }^{7}$ Targeting the sickle cell mRNA transcripts by antisense RNA technology has been augmented as a holistic approach to reducing the levels of $\mathrm{HbS}$ polymerization associated with SCD. ${ }^{8}$ An initial challenge to gene therapy methods have been overcome, and efficient transduction of hematopoietic stem cells with lentiviral vectors has become adverse and preclinical laboratory investigations are evolving for patients with SCD. ${ }^{9}$ The current definitive clinical approach relies upon hydroxyurea and providing supportive care. ${ }^{10}$ Other in-silico studies showed that the genetic variations could alter the expression and function of the hemoglobin gene. Alanazi, Abduljaleel ${ }^{11}$ found that $80 \%$ of the non-synonymous single nucleotide polymorphisms in the HBB gene were deleterious which may affect protein function.

Our in-silico studies highlight a notable way on changes in bond lengths, bond angles, and mutational analyses of hemoglobin molecule that result in reduced oxygencarrying capacity of globin protein. We further investigated the impact of sickle cell mutation on various biological interactions of the normal hemoglobin.

\section{MATERIALS AND METHODS}

\section{Data Collection and Protein Structure Visualization}

The structures of normal hemoglobin molecules in humans and its mutated form (i.e. sickle cell hemoglobin) were downloaded from www.rcsb.org/pdb having PDB id: $2 \mathrm{HHB}$ and $2 \mathrm{HBS}$ respectively. Both the normal and the mutated protein structures were visualized using RasWin and Molegro Molecular Viewer tools for analysis of the $3 \mathrm{D}$ crystallized structures.

\section{Computational analysis of protein structure}

Swiss PDB Viewer v4.1.0 was used to analyze the $\beta$-globin chain of the hemoglobin protein in both normal (HHB) and mutated $(\mathrm{HbS})$ structures, particularly at the site of mutation, i.e. the $6^{\text {th }}$ amino acid amino acid position, where Glu6 is replaced by Val6. ${ }^{12}$ The structural differences between the two types of protein were calculated for different atomic positions within the amino acids on the basis of bond lengths and bond angles. Molegro Molecular Viewer was further used to corroborate the data generated.

\section{Energy minimization study}

The two different protein structures HHB and HbS were subjected to energy minimization studies to evaluate the energy of the atoms in the space of the hemoglobin protein. The energy minimization studies were achieved by GROMOS96 implementation of Swiss- PBD Viewer v4.1.0 for comparison between the two protein structures to detect the stability of the proteins. ${ }^{12}$ The GROMOS molecular simulation package for energy minimization incorporates a force field of energy interactions amongst all the interacting amino acids based on their 3D representation which enabled the study of individual amino acids, particularly the amino acids in and around the $6^{\text {th }}$ position (Glu6 for $\mathrm{HbA}$ and Val6 for $\mathrm{HbS}$ ).

In silico prediction of inter-relationships of $\mathrm{HbB}$ gene with other genes for functional assessment

Prediction of the inter-relationship between HBB gene coding for Hemoglobin $\beta$-chain and several other genes present in a large associated functional dataset and assays were computed with the help of GeneMANIA server, a web-interface online tool for analyzing gene function. The physical protein-protein interactions and genetic interactions were studied through BioGRID and PathwayCommons database, which documented similar associations. Co-expression of $\mathrm{HBB}$ gene with other gene sets were predicted with the help of expression studies referenced in Gene Expression Omnibus (GEO) (WardeFarley, D., S. L. Donaldson, et al. 2010).

\section{RESULTS AND DISCUSSION}

In silico identification of functional parameters - Bond lengths (Distance) and bond angles using Swiss PDBviewer and Molegro molecular viewer

The mutation in hemoglobin disrupts the structural conformity of red blood cells which affects the flow of 
oxygenated blood to body tissues, leading to a detrimental disease called Sickle Cell Anemia. The bond lengths between Pro5-Glu6 in HbA and Pro5-Val6 in HbS of $\beta$-chain are $1.33 \AA$ and $1.33 \AA$ A respectively which do not show any alteration. However, a change is observed between Glu6-Glu7 (HbA) and Val6-Glu7 (HbS) with variable bond lengths of $1.32 \AA ̊$ and $1.33 \AA$ respectively (Figure 1).

Further, the bond angles between Pro5-Glu6 (HbA) change from $119.35^{\circ}$ to $122.4^{\circ}$ in Pro5-Val6 (HbS) and between Glu6-Glu7 ( $\mathrm{HbA}$ ), it changes from $111.93^{\circ}$ to $121.88^{\circ}$ in Val6-Glu7 (HbS) (Figure 2). All the structural and conformational interpretations measured using Swiss PDB-viewer are shown in (Table 1).
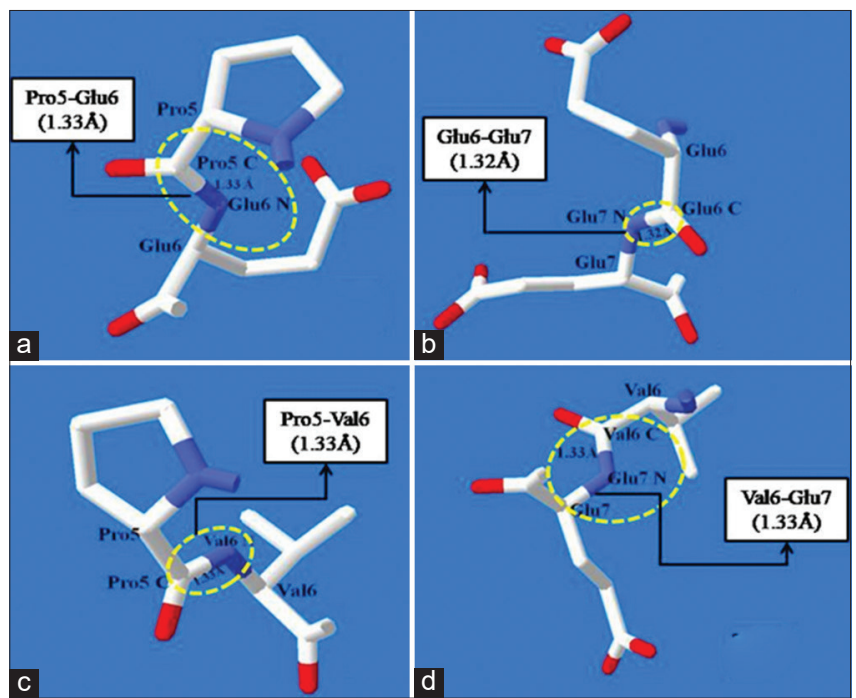

Figure 1: (a) Bond length between Pro5-Glu6 (1.33Å) of HbA protein (b) Glu6-Glu7 (1.32Å) of HbA protein (c) Bond length between Pro5Val6 (1.33Å) of HbS protein (d) Val6-Glu7 (1.33Å) of HbS protein using Swiss PDB Viewer
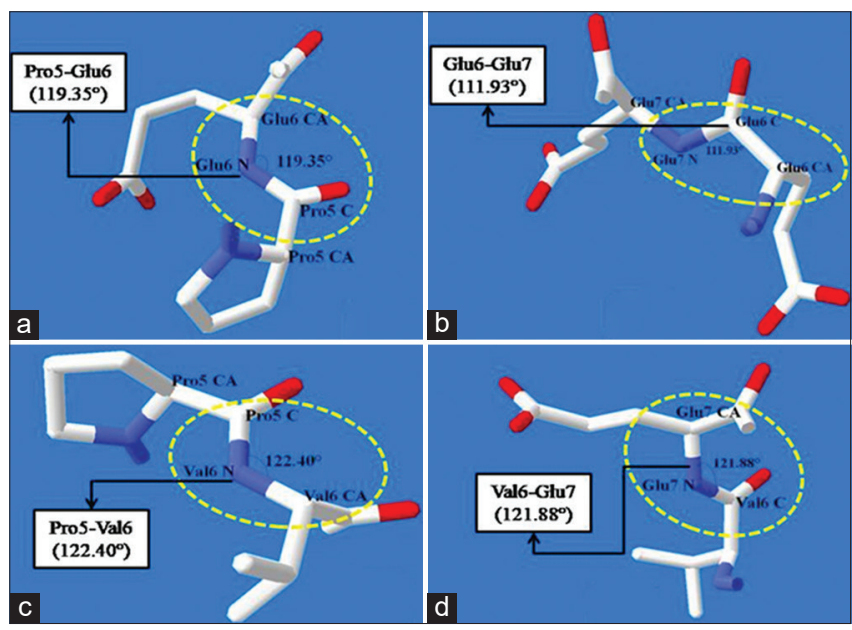

Figure 2: (a) Bond angle between Pro5-Glu6 (119.35 ) of $\mathrm{HbA}$ protein (b) Glu6-Glu7 (111.93 ) of $\mathrm{HbA}$ protein (c) Bond length between Pro5Val6 $\left(122.40^{\circ}\right)$ of HbS protein (d) Val6-Glu7 $\left(121.88^{\circ}\right)$ of $\mathrm{HbS}$ protein using Swiss PDB Viewer
Change in bond lengths and angles result in increasing or decreasing bond enthalpies which in turn affects the stability of the amino acid. Bond angles are less restrained than bond lengths and as such show more variation than bond lengths. Increase in bond angle between three adjacent atoms after mutation from Glu6 $\rightarrow$ Val6 signifies a change in enthalpy and electronegativity wherein electron cloud of the atoms are dispersed further apart spatially. ${ }^{13}$ Glutamate is a polar, negatively charged and hydrophilic amino acid which is involved in binding ligands due to its presence in active sites of protein. But valine is a hydrophobic, $\mathrm{C} \beta$ branched amino acid with reduced freedom for conformational changes within the backbone chain, thereby restricting their secondary structure to mainly $\beta$-sheets. This mutation would affect the binding stability and salt bridge formation ability of hemoglobin. ${ }^{14}$ These different structural changes in conformation of the hemoglobin protein provide an in-depth understanding of the impact of deletion of one amino acid on the oxygen transportation and binding affinity of the hemoglobin protein. Functional parameters like bond lengths and bond angles ascertain the relative importance of non-synonymous mutation on protein's structure and function.

The bond lengths and bond angles of $\mathrm{HbA}$ and $\mathrm{HbS}$ were studied using Molegro Molecule viewer (Table 2). The bond length between Pro5-Glu6 changed from 1.33 (normal HbA) to $1.327 \AA$ in Pro5-Val6 (HbS) and that of Glu6-Glu7 changed from $1.32 \AA$ (normal HbA) to $1.328 \AA$ in Val6-Glu7 (HbS) (Figure 3).

Structural alterations provided a more focused interpretation of the bond angles between Pro5-Glu6 which changed from $119.35^{\circ}$ (normal HbA) to $122.4^{\circ}$ in Pro5-Val6 ( $\mathrm{HbS})$. Moreover, in $\mathrm{HbA}$ and $\mathrm{HbS}$, the bond angle altered significantly from $111.93^{\circ}$ (Glu6-Glu7) to $121.88^{\circ}$ (Pro5-Val6) respectively (Figure 4). This investigation characterized the impact of bond length and bond angle changes distort the structural integrity of the $\mathrm{HbA}$ protein resulting in abnormal, rigid and distorted RBCs. ${ }^{4}$ Evidently, it was reported that bond length provides appropriate information about the mechanism of cooperativity and affinity for oxygen molecule. ${ }^{15}$ But the axial distance between the $\alpha 1$ chain of Pro114 and $\alpha 2$ of Glu116 residues were found to be $3.71 \AA$ and $3.91 \AA$ respectively, and between $\beta 1$ of Glu121 and $\alpha 2$ of Pro114 were $3.71 \AA$ and $3.79 \AA$. The unique contacts were formed by tetramer 1 and 2 of $\mathrm{HbA} .{ }^{16}$

The three-dimensional visualization of ribbon structure of hemoglobin protein and its mutated version is displayed using RasMol (figure. 5a and 5b). This relevant analysis observed from three concurrently used bioinformatics tools provided insight into detection of functional 


\begin{tabular}{|c|c|c|c|c|c|c|c|}
\hline$\beta$-chain of Protein & $\begin{array}{l}\text { PDB } \\
\text { Code }\end{array}$ & $\begin{array}{l}\text { Wild-type } \\
\text { amino acids }\end{array}$ & $\begin{array}{l}\text { Mutated Amino } \\
\text { acids }\end{array}$ & Atom Name & $\begin{array}{l}\text { Amino acids } \\
\text { position }\end{array}$ & $\begin{array}{c}\text { Bond } \\
\text { Length }(\hat{A})\end{array}$ & $\begin{array}{l}\text { Bond } \\
\text { Angles }\end{array}$ \\
\hline \multirow[t]{2}{*}{ Normal Hemoglobin } & $2 \mathrm{HHB}$ & Glu6 & - & PRO5 C6- GLU6 N7 & Pro5-Glu6 & 1.33 & $119.35^{\circ}$ \\
\hline & & & & GLU6 CA6- GLU7 N7 & Glu6-Glu7 & 1.32 & $111.93^{\circ}$ \\
\hline \multirow[t]{2}{*}{ Sickle Cell Hemoglobin } & $2 \mathrm{HBS}$ & & Val6 & PRO5 C6- VAL6 N7 & Pro5-Val6 & 1.33 & $122.4^{\circ}$ \\
\hline & & & & VAL6 C6- GLU7 N7 & Glu7-Val6 & 1.33 & $121.88^{\circ}$ \\
\hline
\end{tabular}

\begin{tabular}{|c|c|c|c|c|c|c|c|}
\hline$\beta$-chain of Protein & $\begin{array}{l}\text { PDB } \\
\text { Code }\end{array}$ & $\begin{array}{l}\text { Wild-type } \\
\text { amino acids }\end{array}$ & $\begin{array}{l}\text { Mutated } \\
\text { Amino acids }\end{array}$ & Atom Name & $\begin{array}{l}\text { Amino acids } \\
\text { position }\end{array}$ & $\begin{array}{c}\text { Bond } \\
\text { Length(Á) }\end{array}$ & $\begin{array}{c}\text { Bond } \\
\text { Angles }\end{array}$ \\
\hline \multirow[t]{2}{*}{ Normal Hemoglobin } & $2 \mathrm{HHB}$ & Glu6 & ---- & PRO5 C6- GLU6 N7 & Pro5-Glu6 & 1.33 & $119.35^{\circ}$ \\
\hline & & & & GLU6 CA6- GLU7 N7 & Glu6-Glu7 & 1.32 & $111.93^{\circ}$ \\
\hline \multirow[t]{2}{*}{ Sickle Cell Hemoglobin } & $2 \mathrm{HBS}$ & & Val6 & PRO5 C6- VAL6 N7 & Pro5-Val6 & 1.327 & $122.4^{\circ}$ \\
\hline & & & & VAL6 C6- GLU7 N7 & Glu7-Val6 & 1.328 & $121.88^{\circ}$ \\
\hline
\end{tabular}
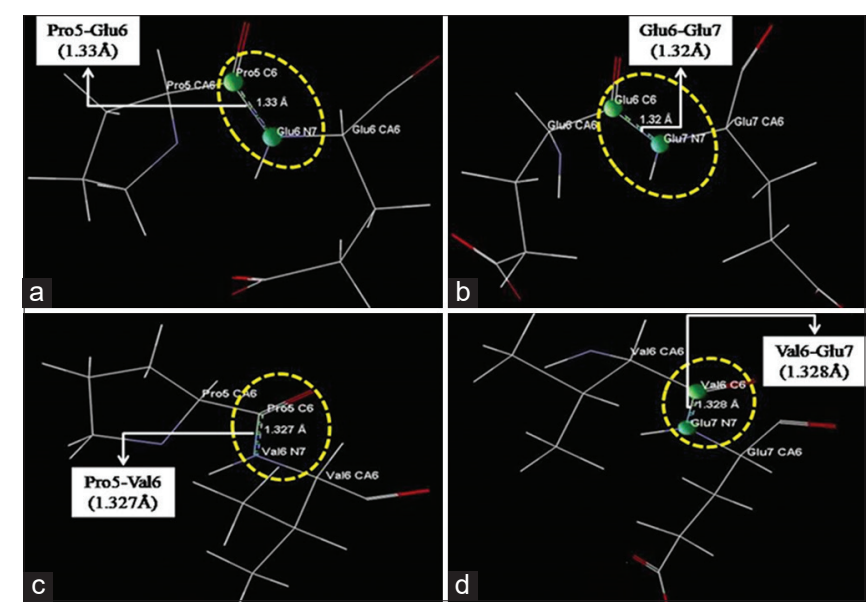

Figure 3: (a) Bond length between Pro5-Glu6 (1.33Å) of $\mathrm{HbA}$ protein (b) Glu6-Glu7 (1.32 $\AA$ ) of $\mathrm{HbA}$ protein (c) Bond length between Pro5-

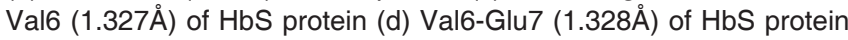
using Molegro Molecular Viewer
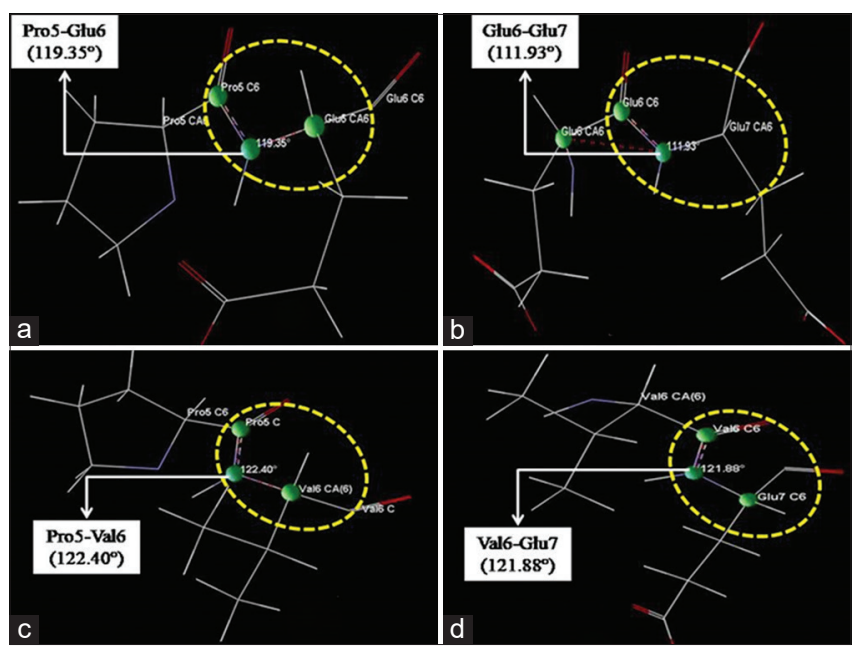

Figure 4: (a) Bond angle between Pro5-Glu6 $\left(119.35^{\circ}\right)$ of $\mathrm{HbA}$ protein (b) Glu6-Glu7 (111.93 $)$ of $\mathrm{HbA}$ protein (c) Bond length between Pro5Val6 $\left(122.40^{\circ}\right)$ of $\mathrm{HbS}$ protein (d) Val6-Glu7 $\left(121.88^{\circ}\right)$ of $\mathrm{HbS}$ protein visualizations using Molegro Molecular Viewer

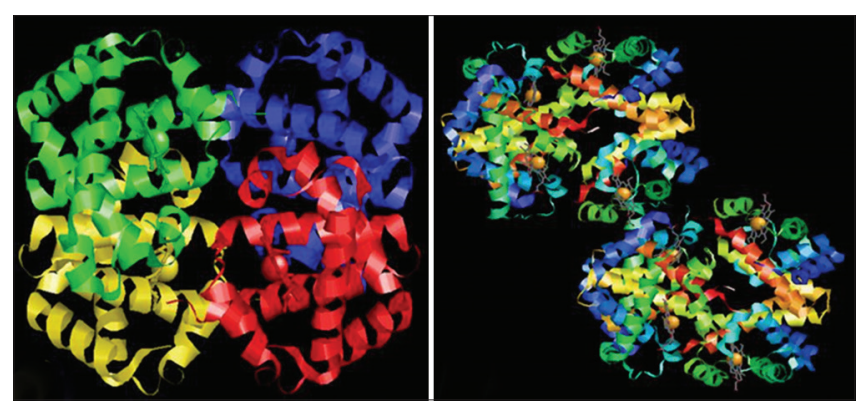

Figure 5: Visualization of Ribbon structure of the two proteins using Rasmol (a) four chains of Normal Hemoglobin protein (2HHB) ( $\alpha$-chain: red, $\beta$-chain: blue, $\gamma$-chain: yellow and $\delta$-chain: green) and (b) Mutated hemoglobin Protein (2HBS)

differences at the structural level. Thus, the present observations are in accordance with the fact that mutation in $\mathrm{HbA}$ protein leads to Sickle Cell Disease. But in one study, the prediction of biological process and molecular function of normal hemoglobin and sickle hemoglobin was found to be similar. ${ }^{17}$ The polymerization reaction leading to the sickling effect of $\mathrm{HbA}$ to become $\mathrm{HbS}$ had been revealed using $\mathrm{HbA}$ expression system in bacteria ${ }^{18}$ and fung $1^{19}$ by site-directed mutagenesis of $\beta$ chains of $\mathrm{HbA}$. Alternatively, it has been seen that, by recruiting homologous recombination pathway through providing a non-mutant $\beta$ globin gene template, a repair mechanism of mutant or diseased causing region could be initiated. ${ }^{20-28}$

Impact of Energy minimization on $\beta$-globin protein It has been observed that the total energy for native type protein structure $(2 \mathrm{HHB}$ ) was $-8311.889 \mathrm{KJ} / \mathrm{mol}$ and the mutant type protein (HBS) was $-33546.063 \mathrm{KJ} / \mathrm{mol}$. After implementing energy minimization using GROMOS96 force field with an exhaustiveness of 100 steepest descent, the energy of $2 \mathrm{HHB}$ was $-26309.943 \mathrm{KJ} / \mathrm{mol}$ and of $2 \mathrm{HBS}$ was $-54317.750 \mathrm{KJ} / \mathrm{mol}$ respectively (Table 3 ). Evidently, Alanazi, Abduljaleel ${ }^{11}$ checked the stability of protein 


\begin{tabular}{|c|c|c|c|c|c|c|c|}
\hline$\beta$-Globin Protein & Residue & Bonds & Angles & Torsion & Non-Bonded & Electrostatic & Total $\mathrm{E}=$ \\
\hline \multicolumn{8}{|c|}{ Individual residues around $6^{\text {th }}$ amino acid position before energy minimization } \\
\hline \multirow[t]{3}{*}{$\mathrm{HbA}$} & Pro B5 & 2.653 & 8.201 & 34.768 & -18.05 & -27.15 & 1.430 \\
\hline & Glu B6 & 3.714 & 7.808 & 9.335 & -11.74 & 29.41 & 41.369 \\
\hline & Glu B7 & 4.340 & 2.939 & 4.294 & -35.90 & 3.44 & -17.602 \\
\hline \multirow{3}{*}{$\mathrm{HbS}$} & Pro B5 & 2.809 & 20.952 & 11.953 & -10.46 & -27.18 & -1.427 \\
\hline & Val B6 & 0.924 & 1.636 & 1.040 & -0.09 & 6.89 & 10.526 \\
\hline & Glu B7 & 0.986 & 2.825 & 2.506 & -34.10 & 2.42 & -25.228 \\
\hline \multicolumn{8}{|c|}{ Individual residues around $6^{\text {th }}$ amino acid position after energy minimization } \\
\hline \multirow[t]{3}{*}{$\mathrm{HbA}$} & Pro B5 & 0.457 & 14.522 & 20.232 & -23.67 & -29.24 & -15.879 \\
\hline & Glu B6 & 1.037 & 9.941 & 6.680 & -29.50 & 16.59 & 8.78 \\
\hline & Glu B7 & 0.422 & 1.197 & 5.463 & -45.56 & -6.23 & -43.921 \\
\hline \multirow[t]{3}{*}{$\mathrm{HbS}$} & Pro B5 & 0.520 & 18.328 & 15.962 & -20.84 & -27.83 & -11.532 \\
\hline & Val B6 & 1.357 & 3.735 & 1.747 & -18.85 & -0.88 & -9.083 \\
\hline & Glu B7 & 0.352 & 2.388 & 2.476 & -45.40 & -2.46 & -41.448 \\
\hline
\end{tabular}

\begin{tabular}{lll}
\multicolumn{3}{l}{ Table 4: } \\
co-expressed whith HBB gene network \\
Symbol & Description & Co-expression \\
\hline HBD & Hemoglobin Subunit Delta & Yes \\
HBZ & Hemoglobin Subunit Zeta & No \\
HBG1 & Hemoglobin Subunit Gamma 1 & Yes \\
HBE1 & Hemoglobin Subunit Epsilon 1 & Yes \\
NFE2 & Nuclear Factor, Erythroid 2 & Yes \\
GDAP1 & Ganglioside Induced & No \\
& Differentiation Associated & \\
& Protein 1 & \\
HBA1 & Hemoglobin Subunit Alpha 1 & Yes \\
HSPA1A & Heat Shock Protein Family A & No \\
& (Hsp70) Member 1A & \\
HBG2 & Hemoglobin Subunit Gamma 2 & No \\
HBA2 & Hemoglobin Subunit Alpha2 & Yes \\
SELT & Selenoprotein T & No \\
HBQ1 & Hemoglobin Subunit Theta 1 & Yes \\
HBM & Hemoglobin Subunit Mu & Yes \\
ALAS2 & 5'-aminolevulinate synthase 2 & Yes \\
PRDX2 & Peroxiredoxin 2 & No \\
ALDOA & Aldolase, fructose-bisphoshate A & Yes \\
HP & Haptoglobin & No \\
DACH1 & Dachshund family transcription & No \\
& factor 1 & \\
PF4 & Platelet Factor 4 & Yes \\
MB & Myoglobin & Yes \\
\hline & &
\end{tabular}

structure for solvent accessibility of amino acid residue and found that the total energy of native protein structure $(4 \mathrm{HHB})$ and mutant type structures were $-334380.5 \mathrm{~kJ} / \mathrm{mol}$. The structural variations could be visualized on the basis of the energy variations of Glu6 and Val6 of HbA and $\mathrm{HbS}$ proteins respectively. While Glu6 had a net energy of $41.369 \mathrm{KJ} / \mathrm{mol}$ which was minimized to $8.78 \mathrm{KJ} / \mathrm{mol}$ following GROMOS96 calculations, the net energy of Val6 was minimized to $-9.083 \mathrm{KJ} / \mathrm{mol}$ from $10.526 \mathrm{KJ} / \mathrm{mol}$ (Table 3). In Sickle Cell Disease, there is a decreasing tendency of metabolic processes to control oxidative stress which results in free radical generation thereby impairing sugar phosphate pathways. This results in energy deficiencies in critical metabolic systems as a consequence of oxygen deprivation to red blood cells, thereby leading to irreversible damage of membrane and ionic channels of sickled erythrocytes. ${ }^{29}$ Since the net energy of Glu6 is higher than Val6 even after minimization process, it could be inferred that Glu6 is more reactive in nature than Val6 which ultimately affects the binding of red blood cells with oxygen moieties during oxidative stress.

Functional activity detection of wild-type normal protein (HBB gene) through GeneMANIA Server The genes that are co-expressed and have physical interactions or properties are shown in Figure 6a and 6b, and the description of the genes co-expressed with $\mathrm{HBB}$ network is listed in Table 4. The HBB network gene function and its appearance in network and genome are listed in Table 5. Gene network functional assessment on the basis of Gene Ontology data generated several composite functions of $\mathrm{HBB}$ gene which has specific role in blood microparticle association, i.e., its presence in RBCs, its role in gaseous transport, its response to reactive oxygen species, hydrogen peroxide and oxidative stress and its antioxidant activity within the cellular environment. It was reported that there exists functional interactions between VCAM-1 gene and other similarly related genes which plays a major role in cell adhesion binding, membrane docking, microvillus and leukocyte cell-cell adhesion. ${ }^{30}$

Genes of the HBB network involved in blood microparticle formation were HBD, HBA1, HBG2, HBE1, HP, and HSPA1A (Table 4, Table 5) which corresponds to 108 genes within the genome associated with the similar function. Microparticles (MPs) in blood are generated from 


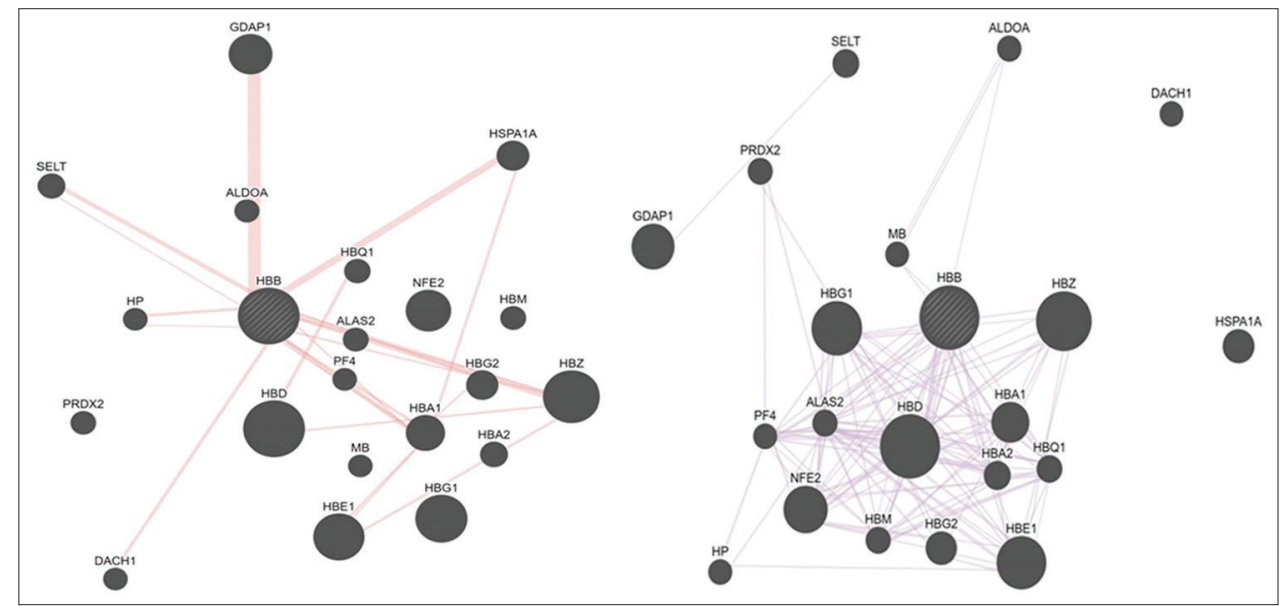

Figure 6: (a) Genes that have physical interaction with HBB gene and (b) Genes co-expressed with HBB gene

Table 5: Table shows the HBB network genes functions and its appearance in network and genome

\begin{tabular}{llcc}
\hline Features & FDR & Genes in network & Genes in Genomes \\
\hline Blood microparticle & $2.73 \mathrm{e}-7$ & 7 & 108 \\
Hydrogen Peroxide Catabolic Process & $9.52 \mathrm{e}-6$ & 4 & 14 \\
Cytoplasmic membrane-bounded vesicle lumen & $5.85 \mathrm{e}-5$ & 5 & 76 \\
Vesicle lumen & $5.85 \mathrm{e}-5$ & 5 & 76 \\
Hydrogen Peroxide Metabolic Process & $5.85 \mathrm{e}-5$ & 4 & 25 \\
Cellular response to Hydrogen Peroxide & $1.64 \mathrm{e}-4$ & 4 & 35 \\
Response to Hydrogen Peroxide & $2.44 \mathrm{e}-4$ & 4 & 40 \\
Gas Transport & $3.11 \mathrm{e}-4$ & 3 & 10 \\
Cellular response to reactive oxygen species & $8.69 \mathrm{e}-4$ & 4 & 58 \\
Endocytic vesicle lumen & $1.16 \mathrm{e}-3$ & 3 & 16 \\
Response to reactive oxygen species & $1.91 \mathrm{e}-3$ & 4 & 74 \\
Cellular response to oxidative stress & $4.40 \mathrm{e}-3$ & 4 & 95 \\
Reactive oxygen species metabolic process & $4.40 \mathrm{e}-3$ & 4 & 95 \\
Oxidoreductase activity, acting on peroxide as receptor & $6.75 \mathrm{e}-3$ & 3 & 32 \\
Peroxidase activity & $6.75 \mathrm{e}-3$ & 3 & 32 \\
Response to inorganic substance & $2.37 \mathrm{e}-2$ & 4 & 153 \\
Response to oxidative stress & $2.41 \mathrm{e}-2$ & 4 & 56 \\
Antioxidant activity & $2.77 \mathrm{e}-2$ & 3 & \\
\hline
\end{tabular}

FDR: False discovery rate (If FDR is greater than or equal to the probability that this is a false positive, then it will lead to incorrect rejection of hypothesis)

various cell types including erythrocytes and elevated levels of blood MPs in Sickle Cell Anemia has been observed in patients which lead to activation of blood clotting through thrombin generation. ${ }^{31}$ The various metabolic and cellular responses to reactive oxygen species and oxidative stress were governed by the HBB, HBA1, PRDX2 and HP networks for providing functional capabilities to hemoglobin beta subunit for oxygen transport. The antioxidant activity, oxidoreductase activity, and peroxidase activity also involve the network of $\mathrm{HBB}$, HBA1 and PRDX2 genes. Involvement of HBB and HBA1 genes of hemoglobin molecule suggests their role in oxidative transportation and metabolic redox reactions within the body. The networks with featured functions depict the networking of $\mathrm{HBB}$ and HBA1 in all the demonstrated activities along with their co-expressivity during gene function (Table 4). However, despite sharing network activity in critical functions of oxidative responses and reactive oxygen species, $\mathrm{HP}$ and PRDX2 do not co-express with HBB.

As a result of these interactive genes involved in a network performing a common metabolic function, a mutation in any one of them could lead to complete network disruption resulting in loss of function and bioprocess system disintegration as characterized by Sickle Cell Disease (Table 6). $\beta$-haemoglobinopathies of the HBB gene, particularly $\mathrm{HbC}, \mathrm{HbD}, \mathrm{HbE}$ and $\mathrm{HbS}$ have been reported to express abnormal molecular interactions within protein chains and also with external ligands which disrupt binding and transport of oxygen across cells. ${ }^{11}$ Moreover, single nucleotide polymorphisms and genome variants in $\mathrm{Hb}$ generally do not lead to life-threatening conditions but certain mutations do cause structural and biochemical alterations that cause severe anemia. ${ }^{32}$ 
Table: 6 Summary of the normal and each of the abnormal mutated hemoglobin

\begin{tabular}{lclll} 
Hemoglobin HB disorder & Position chromosome 11 & Mutational position & Mutation & Biological process \\
\hline HHB & & None & None & Oxygen Transportation \\
HB S & 6 & Beta 6 & Glu-Val(E $\rightarrow$ V) & Oxygen Transportation \\
HB C & 6 & Beta 6 & Glu-Lys $(\mathrm{E} \rightarrow$ K) & Oxygen Transportation \\
HB E & 26 & Beta 26 & Glu-Lys(E $\rightarrow$ K) & Oxygen Transportation \\
HB D & 121 & Beta 121 & Glu-Gln(E $\rightarrow$ Q) & Oxygen Transportation \\
\hline
\end{tabular}

\section{CONCLUSION}

Structural aberrations in wild form of hemoglobin disrupt the normal functioning of erythrocytes resulting in oxygen deprivation and severe anemia. A comparative analysis of the spatial 3D structure of $\mathrm{HbA}$ and $\mathrm{HbS}$ was done which revealed that there is a significant structural difference in terms of both bond lengths and bond angles between the two proteins when glutamine is mutated to valine due to point mutation. A significant compromise of the structural integrity of the sickle cell hemoglobin impairs the oxygen binding capacity of hemoglobin due to its transformation into a sickle shape. Dynamic energy calculations and net minimization studies provided a clear picture regarding the reactivity and cooperativity of hemoglobin. The HbA molecule had a much higher net energy value $(-26309.943 \mathrm{KJ} / \mathrm{mol})$ than its $\mathrm{HbS}$ counterpart $(-54317.750 \mathrm{KJ} / \mathrm{mol})$ substantiating the reactive capacity of $\mathrm{HbA}$. Even the mutated amino acids at the $6^{\text {th }}$ position of the beta chain had significantly variable total energy values $\left(\mathrm{E}_{\text {Total }}=8.78 \mathrm{KJ} / \mathrm{mol}\right.$ for Glu6, $\mathrm{E}_{\text {Total }}=-9.083 \mathrm{KJ} / \mathrm{mol}$ for Val6). The protein-protein physical and interactions and co-expression of HBB genes using GeneMania server shed light into the diverse functional modalities of $\mathrm{HbA}$. HBB gene shared a common network function spread across a wide array of genes with HBA1 gene which also encodes for $\mathrm{HbA}$ protein, which explains the shared metabolic functions related to their gene ontology. The gene co-expression study further strengthened the functional relatedness of $\mathrm{HBB}$ and $\mathrm{HBA} 1$ genes in $\mathrm{HbA}$ protein. The overall computational study inferred that sickle cell disease is a systemic condition wherein a chain event within the metabolic process are affected due to the single nucleotide (GAG $\rightarrow$ GTG) resulting in a cascade of events that culminate into severe anemia. More in silico studies are needed on a broader scale to decipher the molecular mechanisms involved in the manifestation of this disease for a better chance of targeted drug designing and precision therapy.

\section{REFERENCES}

1. Stuart MJ and Setty BY. Sickle cell acute chest syndrome: pathogenesis and rationale for treatment. Blood 1999; 94(5):1555-1560.

https://doi.org/10.1182/blood.V94.5.1555.417k36_1555_1560
2. Sommer CK, Goldbeck AS, Wagner SC and Castro SM. Neonatal screening for hemoglobinopathies: one-year experience in the public health network in Rio Grande do Sul, Brazil. Cad Saúde Pública 2006; 22(8):1709-1714.

https://doi.org/10.1590/S0102-311X2006000800019.

3. Ashley-Koch A, Murphy CC, Khoury MJ and Boyle CA. Contribution of sickle cell disease to the occurrence of developmental disabilities: a population-based study. Genetics in Medicine 2001; 3(3):181-186. 10.1097/00125817-20010500000006.

4. Saxena P, Dhiman P, Bihari C and Rastogi A. Sickle cell trait causing splanchnic venous thrombosis. Case reports in hepatology 2015; 743289.

https://doi.org/10.1155/2015/743289

5. Serjeant GR. Mortality from sickle cell disease in Africa. BMJ 2005; 330 (7489):432.

https://doi.org/10.1136/bmj.330.7489.432

6. Piel FB, Patil AP, Howes RE, Nyangiri OA, Gething PW, Williams TN, et al. Global distribution of the sickle cell gene and geographical confirmation of the malaria hypothesis. Nature Commun 2010; 1 :

https://doi.org/104. 10.1038/ncomms1104

7. Serjeant GR, Ceulaer CD, Lethbridge R, Morris J, Singhal A and Thomas PW. The painful crisis of homozygous sickle cell disease: clinical features. British journal of haematology 1994; 87(3):586-891.

https://doi.org/10.1111/j.1365-2141.1994.tb08317.x

8. Pace BS, Qian $X$ and Ofori-Acquah S. Selective inhibition of beta-globin RNA transcripts by antisense RNA molecules. Cellular and molecular biology 2004; 50(1):43-51.

9. Hoban MD, Orkin SH and Bauer DE. Genetic treatment of a molecular disorder: gene therapy approaches to sickle cell disease. Blood 2016; 127(7):839-848.

https://doi.org/10.1182/blood-2015-09-618587

10. Yawn BP, Buchanan GR, Afenyi-Annan AN, Ballas SK, Hassell KL, James AH, et al. Management of sickle cell disease: summary of the 2014 evidence-based report by expert panel members. JAMA 2014; 312(10):1033-1048.

11. Alanazi M, Abduljaleel Z, Khan W, Warsy AS, Elrobh M, Khan Z, et al. In silico analysis of single nucleotide polymorphism (SNPs) in human $\beta$-globin gene. PloS ONE 2011; 6(10):e25876. https://doi.org/10.1371/journal.pone.0025876.

12. Guex N, Peitsch MC. SWISS-MODEL and the Swiss-Pdb Viewer: an environment for comparative protein modeling. Electrophoresis 1997; 18(15):2714-2723. https://doi.org/10.1002/elps.1150181505.

13. Laskowski RA, Moss DS and Thornton JM. Main-chain bond lengths and bond angles in protein structures. Journal of molecular biology 1993; 231(4):1049-1067. https://doi.org/10.1006/jmbi.1993.1351.

14. Betts MJ and Russell RB. Amino acid properties and consequences of substitutions. Bioinformatics for geneticists 2003; 317:289-316. 
15. Seixas FAV, Santini TD, Moura VPd and Gandra E. Evaluation of the (haem) $\mathrm{Fe}-\mathrm{N} \square 2$ (HisF8) bond distances from haemoglobin structures deposited in the Protein Data Bank. Acta Crystallographica Section D: Biological Crystallography 2008; 64(9):971-976.

\section{$10.1107 / \mathrm{S} 0907444908022208$}

16. Harrington DJ, Adachi $\mathrm{K}$ and Royer WE. Crystal Structure of Deoxy-Human Hemoglobin $\beta 6$ Glu $\rightarrow$ Trp IMPLICATIONS FOR THE STRUCTURE AND FORMATION OF THE SICKLE CELL FIBER. Journal of Biological Chemistry 1998; 273(49):3269032696. 10.1074/jbc.273.49.32690.

17. Wiwanitkit V. Single amino acid substitution in important hemoglobinopathies does not disturb molecular function and biological process. International journal of nanomedicine 2008; 3(2):225-227.

https://doi.org/10.2147/IJN.S824.

18. Nagai $K$ and Thøgersen, HC. Generation of $\beta$-globin by sequence-specific proteolysis of a hybrid protein produced in Escherichia coli. Nature 1984; 309 (5971):810-812.

19. Wagenbach M, O'Rourke K, Vitez L, Wieczorek A, Hoffman S, Durfee $S$, et al. Synthesis of wild type and mutant human hemoglobins in Saccharomyces cerevisiae. Nature Biotechnology 1991; 9(1):57-61. 10.1038/nbt0191-57.

20. Urnov FD, Rebar EJ, Holmes MC, Zhang HS and Gregory PD. Genome editing with engineered zinc finger nucleases. Nature Reviews Genetics 2010; 11(9):636-646. 10.1038/nrg2842.

21. Cathomen $T$ and Joung JK. Zinc-finger nucleases: the next generation emerges. Molecular Therapy 2008; 16(7):1200-1207. https://doi.org/10.1038/mt.2008.114.

22. Guo J, Gaj T and Barbas III CF. Directed evolution of an enhanced and highly efficient Fokl cleavage domain for zinc finger nucleases. Journal of molecular biology 2010; 400(1):96-107. https://doi.org/10.1016/j.jmb.2010.04.060.

23. Durai S, Mani M, Kandavelou K, Wu J, Porteus MH and Chandrasegaran S. Zinc finger nucleases: custom-designed molecular scissors for genome engineering of plant and mammalian cells. Nucleic acids research 2005; 33(18):5978-5990. https://doi.org/10.1093/nar/gki912.
24. Porteus $\mathrm{MH}$ and Carroll D. Gene targeting using zinc finger nucleases. Nature Biotechnology 2005; 23(8):967-973. 10.1038/ nbt1125.

25. Perez EE, Wang J, Miller JC, Jouvenot Y, Kim KA, Liu O, et al. Establishment of HIV-1 resistance in CD4+ T cells by genome editing using zinc-finger nucleases. Nature Biotechnology 2008; 26(7):808-816. 10.1038/nbt1410.

26. Holt N, Wang J, Kim K, Friedman G, Wang X, Taupin V, et al. Human hematopoietic stem/progenitor cells modified by zincfinger nucleases targeted to CCR5 control HIV-1 in vivo. Nature Biotechnology 2010; 28(8):839-847. 10.1038/nbt.1663.

27. Sander JD, Maeder ML, Reyon D, Voytas DF, Joung JK and Dobbs D. ZiFiT (Zinc Finger Targeter): an updated zinc finger engineering tool. Nucleic acids research 2010; 38(suppl_2):W462-W468. https://doi.org/10.1093/nar/gkq319.

28. Mandell JG and Barbas CF. Zinc Finger Tools: custom DNAbinding domains for transcription factors and nucleases. Nucleic acids research 2006; 34(suppl 2):W516-W523. https://doi.org/10.1093/nar/gkl209

29. Ilesanmi OO. Pathological basis of symptoms and crises in sickle cell disorder: implications for counseling and psychotherapy. Hematology reports 2010; 2(1):e2 https://doi.org/10.4081/hr.2010.e2.

30. Hussain MRM, Shaik NA, Al-Aama JY, Asfour HZ, Khan FS, Masoodi TA, et al. In silico analysis of Single Nucleotide Polymorphisms (SNPs) in human BRAF gene. Gene 2012; 508(2):188-196. https://doi.org/10.1016/j.gene.2012.07.014.

31. Falanga $A$ and Trinchero $A$. Circulating microparticles in children with sickle cell anemia: a heterogeneous procoagulant storm directed by hemolysis and fetal hemoglobin. Haematologica 2013; 98(7):995-997. https://doi.org/10.3324/haematol.2013.085779.

32. Thom CS, Dickson CF, Gell DA and Weiss MJ. Hemoglobin variants: biochemical properties and clinical correlates. Cold Spring Harbor perspectives in medicine 2013; 3(3): a011858 10.1101/cshperspect.a011858.

\section{Authors Contribution:}

SN-Concept and design of the study; interpreted the results, prepared first draft of manuscript and critical revision of the manuscript; NP- Statistically analyzed and interpreted; reviewed the literature and manuscript preparation; MN- Design of the study, statistically analyzed and interpreted, preparation of manuscript and revision of the manuscript; BD- Concept and coordination of the overall study.

Work attributed to:

Bioinformatics Centre, Gurucharan College, Silchar, Assam, India

Orcid ID:

Soumitra Nath- (1) https://orcid.org/0000-0003-3678-2297

Nirmal Paul- io https://orcid.org/0000-0002-6503-0273

Manabesh Nath- io https://orcid.org/0000-0001-5979-8377

Bibhas Deb- (1) https://orcid.org/0000-0002-3899-5897 